\title{
Formação das primeiras estrelas e as condições para a formação de vida no universo jovem.
}

Jean W. P. Claudino (IC), João V. C. Rocha (IC).

\section{Resumo}

Em um estudo recente "The Habitable Epoch of the Early Universe" [1], verifica-se a hipótese de que em tempos remotos, quando o Universo datava de 10-17 milhões de anos, havia um ambiente propício para o surgimento da vida. Estudos revelaram que neste Universo Jovem $(100 \leq(1+z) \leq 137)$, as primeiras estrelas começaram a colapsar em supernovas, criando os elementos químicos necessários para a formação dos primeiros planetas rochosos. Através do estudo de conceitos e teorias, será discutida a maneira como o universo se formou e evoluiu, e a compatibilidade do modelo cosmológico com a tendência do surgimento da vida, visto que em tal período a temperatura da radiação cósmica de fundo permanecia entre 273-373K, permitindo que estes planetas possuíssem água na forma líquida, condicionando-os a serem propícios para a existência de vida da maneira como a conhecemos.

Palavras Chave: Cosmologia, Vida, Universo Jovem.

\section{Introdução}

Combinando as ideias da formação de planetas rochosos e a possível existência de água nos mesmos, bem como outros conceitos mais complexos, Abraham Loeb tenta demonstrar em seu artigo "The Habitable Epoch of the Early Universe" [1], que em épocas remotas, todo Universo poderia ser habitável. O objetivo desse projeto é entender todos os conceitos por trás do artigo, bem como confirmar sua ideia principal.

\section{Resultados e Discussão}

Tendo em vista a larga gama de pontos que devem ser consideradas para uma adequada análise da possibilidade de existência de vida no Universo, inicialmente é importante esclarecer que se considerou "vida" tal qual se é conhecida na Terra, ou seja, dependente de água no estado líquido. Dessa forma, os trabalhos de pesquisa foram divididos em duas partes:

- Procurou-se inicialmente, numa abordagem alternativa a Relatividade Geral, usando a equação de Friedmann mostrada abaixo, estabelecer um esboço de um diagrama termal do Universo, possibilitando encontrar um período do cosmos em que a Radiação Cósmica de Fundo estivesse em torno de $300 \mathrm{~K}$. O resultado, mostrado na Figura 1, aponta algo por volta de 12 milhões de anos.

$$
\left(\frac{\dot{a}}{a}\right)^{2}=\frac{8 \pi G \rho}{3}-\frac{k c^{2}}{a^{2}}
$$

- Estudou-se em seguida a formação e explosão das primeiras estrelas para verificar se na idade do Universo assinalada anteriormente, os elementos necessários para a vida (na forma que a conhecemos) já estavam formados.
Encontrando que tal hipótese era plausível, portanto, em acordo com o apresentado por Loeb em seu artigo [1].

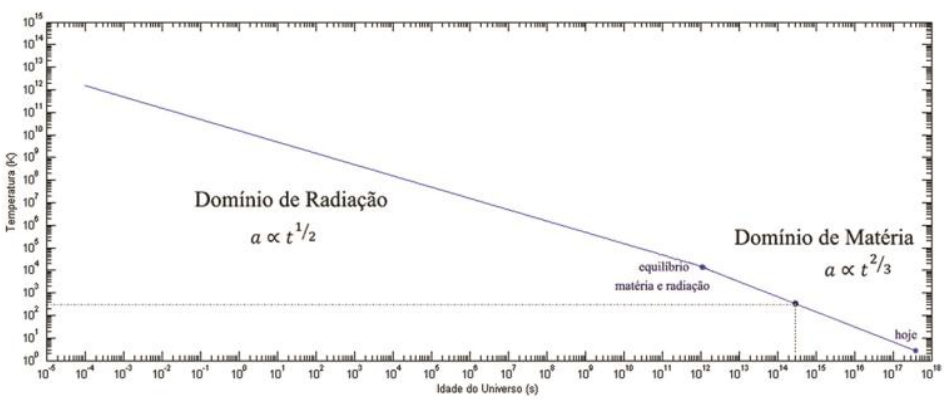

Figura 1. Histórico termal do Universo elaborado a partir da solução da equação de Friedmann.

\section{Conclusões}

A partir dos trabalhos realizados na referida Iniciação Científica, permeando de uma maneira geral assuntos como cosmologia, astrofísica e astrobiologia, foi possível se atingir os objetivos propostos, adquirindo conhecimento necessário para o entendimento do supracitado artigo [1], além de confirmar sua ideia principal.

\section{Agradecimentos}

Ao CNPq pelo financiamento da bolsa de Iniciação Científica e ao orientador do projeto professor Pedro Cunha de Holanda.

[1] LOEB, Abraham; The Habitable Epoch of the Early Universe. preprint arXiv: 1312.0613 .

[2] LIDDLE, Andrew; An Introduction to Modern Cosmology. 2. ed. London: Wiley, 2009. 189p.

[3]MORISON, Ian; Introduction to Astronomy and Cosmology. Wiley, 2008. 362p. 